\title{
How Patient Work Changes Over Time for People With Multimorbid Type 2 Diabetes: Qualitative Study
}

Kathleen Yin ${ }^{1}$, BPharm, PhD; Joshua Jung ${ }^{1}$, BClinSC; Enrico Coiera ${ }^{1}$, MBBS, PhD; Kenneth W K Ho ${ }^{2}$, MBBS, PhD; Sanjyot Vagholkar ${ }^{2}$, MBBS, MPH, PhD; Ann Blandford ${ }^{3}$, MA, PhD; Frances Rapport ${ }^{4}$, BA, MPhil, PhD; Annie Y $\mathrm{S} \mathrm{Lau}{ }^{1}, \mathrm{BE}, \mathrm{PhD}$

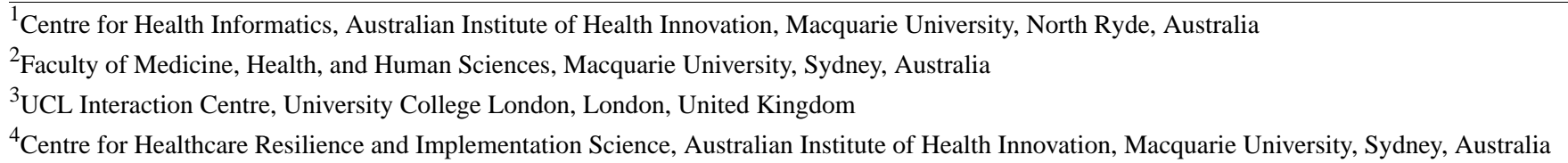

\section{Corresponding Author:}

Kathleen Yin, BPharm, PhD

Centre for Health Informatics

Australian Institute of Health Innovation

Macquarie University

Level 6

75 Talavera Road

North Ryde, 2113

Australia

Phone: 61298502477

Email: kathleen.yin@mq.edu.au

\section{Abstract}

Background: The experiences of patients change throughout their illness trajectory and differ according to their medical history, but digital support tools are often designed for one specific moment in time and do not change with the patient as their health state changes. This presents a fragmented support pattern where patients have to move from one app to another as they move between health states, and some subpopulations of patients do not have their needs addressed at all.

Objective: This study aims to investigate how patient work evolves over time for those living with type 2 diabetes mellitus and chronic multimorbidity, and explore the implications for digital support system design.

Methods: In total, 26 patients with type 2 diabetes mellitus and chronic multimorbidity were recruited. Each interview was conducted twice, and interviews were transcribed and analyzed according to the Chronic Illness Trajectory Model.

Results: Four unique illness trajectories were identified with different patient work goals and needs: living with stable chronic conditions involves patients seeking to make patient work as routinized and invisible as possible; dealing with cycles of acute or crisis episodes included heavily multimorbid patients who sought support with therapy adherence; responding to unstable changes described patients currently experiencing rapid health changes and increasing patient work intensity; and coming back from crisis focused on patients coping with a loss of normalcy.

Conclusions: Patient work changes over time based on the experiences of the individual, and its timing and trajectory need to be considered when designing digital support interventions.

International Registered Report Identifier (IRRID)： RR2-10.1136/bmjopen-2018-022163

(J Med Internet Res 2021;23(7):e25992) doi: 10.2196/25992

\section{KEYWORDS}

patient work; self-management; diabetes; chronic conditions; chronic illness trajectory; consumer informatics 


\section{Introduction}

\section{Background and Significance}

Patient work is defined as health-related tasks and actions a patient undertakes in their self-management of health conditions $[1,2]$. Initially proposed by Corbin and Strauss [3], the concept recognizes that patients conduct a variety of such actions, with tasks ranging from physical to cognitive, ranging from visible to invisible, conducted alone, or requiring assistance from others
[4]. The Chronic Illness Trajectory Model [5], also created by Corbin and Strauss, describes how the course of illness changes over time. Patients may shift between different illness phases repeatedly over their lifetime, as their conditions fluctuate (Figure 1 [5]). This model has been used to describe patients with conditions such as injury rehabilitation [6], metastatic cancer [7], poststroke recovery [8], and multiple sclerosis [9], with evidence suggesting that patient work needs and goals change as participants move between phases [6-8].

Figure 1. The Chronic Illness Trajectory Model.

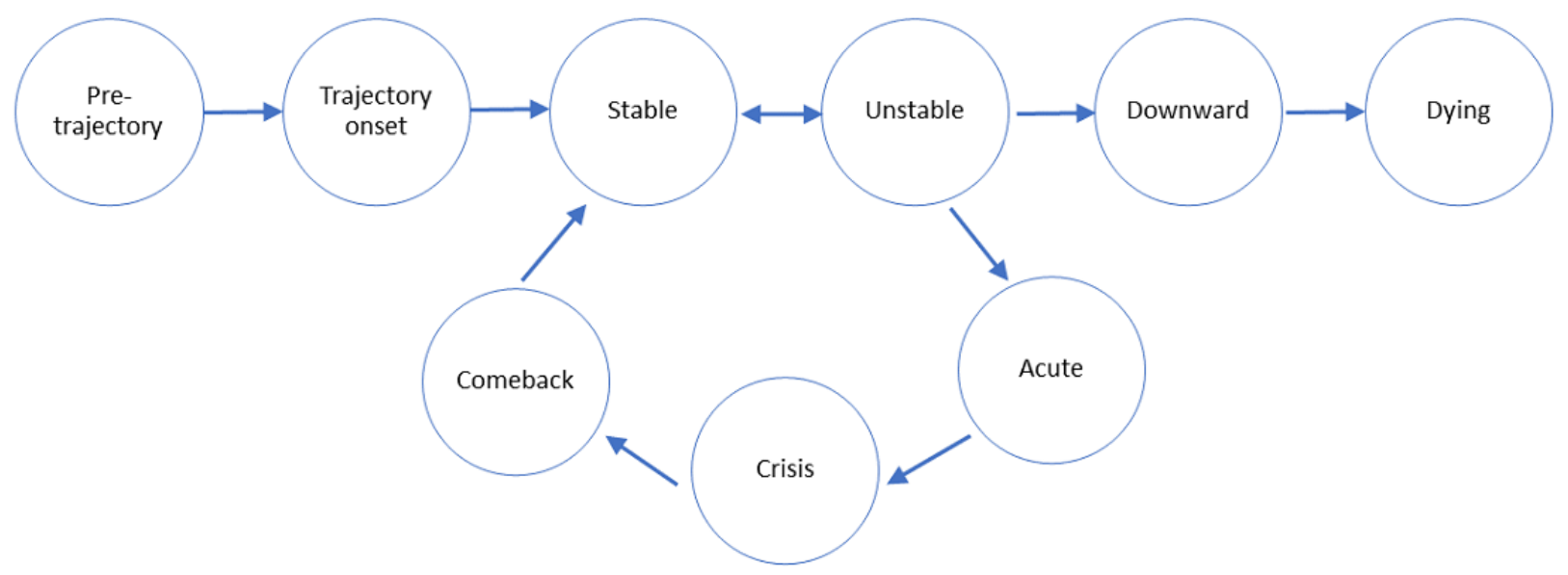

However, current digital technologies for patients with chronic disease struggle to incorporate changing health needs and goals. For example, newly diagnosed patients with type 2 diabetes prefer information on lifestyle alteration and available treatment $[10,11]$, whereas patients with long-term complications, such as established diabetic retinopathy, require strict symptom monitoring [12,13]. Specific subpopulations have significant differences in health care preferences and goals, requiring varied information and recommendations. Studies that assessed targeted subpopulations have revealed that patients at different stages of their health condition have different information preferences [11] and that the use of apps is heavily influenced by contextual factors [14]. As such, patients experience growing out of the apps they took up early in their diagnosis, taking up new apps as they find their health care goals changing over the course of the illness.

Digital systems that are sensitive to the changing needs of their users would be able to help people keep using the same app over time, reducing the need to seek out more appropriate apps and ensuring continued tracking of health care data over time, especially for those who have comorbidities affecting multiple aspects of their health.

Therefore, gaps exist in our understanding of how patient work tasks and patient needs change over the phases of the chronic illness trajectory and how digital health apps can be improved by being designed with such changes in mind. We contribute to solving this issue by identifying the types of tasks patients engage in at different phases of their type 2 diabetes and the types of trajectories patients may experience over time and providing suggestions on how digital interventions could be designed to detect or anticipate changes in illness phases to provide maximum support.

\section{Objective}

In this paper, we examine how patient work tasks and goals change over the chronic illness trajectory, focusing on multimorbid patients with type 2 diabetes mellitus self-managing in the community.

\section{Methods}

\section{Overview}

We undertook interviews of multimorbid community-dwelling patients with type 2 diabetes mellitus, as described in detail in the complete study protocol [15]. Ethics approval was obtained from the Macquarie University Human Research Ethics Committee for Medical Sciences (reference number 5201700718).

\section{Recruitment}

Participants were recruited purposively from endocrinology clinics across metropolitan Sydney. Inclusion criteria were fluency in English, diagnosis of type 2 diabetes mellitus with at least one chronic comorbidity, and ability to legally provide consent.

Potential participants were suggested by clinicians, followed by researchers approaching these patients with a telephone call, explaining the purpose of the study and the processes involved. The researchers then sent a study information pamphlet and consent form via email or mail. If the person agreed to participate, the researcher arranged a time and location for the 
interviews. The researcher did not disclose their professional backgrounds.

In total, 26 participants were interviewed twice. A total of 52 individuals were approached during the recruitment. From the pool of 52 people, $5(10 \%)$ did not meet the selection criteria and were excluded $(2 / 52,4 \%$ did not have comorbidities and 3/52, $6 \%$ did not speak English to the required standard), 6 (12\%) agreed to participate but later withdrew, and 15 (29\%) declined the invitation or were unable to participate.

\section{Data Collection}

Each participant was interviewed on two occasions over 2 consecutive days, with each interview taking approximately 1 hour. Between interviews, participants wore a wearable camera for continuous, unobtrusive observation, as part of a larger study [15].

Interview questions were semistructured and focused on how community-dwelling people with chronic multimorbidity managed health-related tasks and how they modified their daily lives to accommodate their health needs. The interview question guide is provided in Multimedia Appendix 1 and was developed after consultation with the researchers. The interview questions and procedures were pilot tested with 2 participants before participant recruitment.

All participants were interviewed in their homes based on their choice. Many had arranged for family members to be present, with 38\% (10/26) of participants having their spouses present, $4 \%(1 / 26)$ having their child present, $4 \%(1 / 26)$ having their mother present, and $4 \%(1 / 26)$ having their grandchild present. Family members often did not get involved and listened to the conversation. However, they were able to provide information when participants themselves were uncertain and asked for help.

All interviews were conducted by 2 researchers, one of whom was always KY (female), JJ (male), or AYSL (female). All interviews were audio recorded. Field notes were made by the interviewers during the interview to record nonverbal cues and observations inside the dwelling, and notes from both interviewers were consolidated within 24 hours of each interview. The second interview for each patient was conducted by the same researcher pair as in the first interview. The field notes were read alongside interview transcriptions, and any extra information was added to the end of the transcriptions.

\section{Qualitative Data Analysis}

Audio recordings were transcribed externally and imported into NVivo Plus (QSR International, version 12). A thematic analysis was conducted inductively-deductively on all interview transcripts.

KY and JJ coded all transcripts separately and established codes that emerged from the data, which described either the work conducted to manage health or how the experience of self-management changed over time. These emerged codes were then deductively placed into themes that aligned with the phases and trajectories in the Chronic Illness Trajectory Model [5] and patient work tasks established in our previous scoping review [16]. Codes that did not fit into any existing themes in either of the frameworks were then read and placed into emergent themes over multiple readings. These new themes were presented alongside themes derived from the two frameworks.

Interview data were analyzed immediately after each interview to detect data saturation, and recruitment ceased when data saturation was reached (defined when no new patient work tasks were being described by 2 participants in a row). KY and JJ reviewed the codes and the theme framework over 6 months, and any discrepancies were resolved via consensus, with monthly meetings. KY, JJ, and AYSL then conducted design ideation [17-19], with brainstorming and scanning the available literature to consider the possible design implications of each need.

In this paper, we report our findings on patient work tasks and how they fit into the Chronic Illness Trajectory Model. Contextual factors influencing tasks and trajectories are beyond the scope of this study.

\section{Results}

\section{Participant Demographics}

The 26 participants of this study resided across metropolitan Sydney and had a variety of cultural backgrounds (Table 1). The median and mean age were both 72 years (range 46-86), with $61 \%(16 / 26)$ being male and 53\% (14/26) identifying as Anglo Australian. The median and mean number of years diagnosed with type 2 diabetes were 19.5 (range 3-50) years. Less than two-third $(16 / 26,61 \%)$ of the participants were using insulin at the time of the study, and $69 \%(18 / 26)$ were retirees. The most common comorbidities were cardiovascular diseases, dyslipidemia, and kidney conditions, with a mean number of 3.96 comorbidities (range 1-20) per person. 
Table 1. Participant demographics data $(\mathrm{N}=26)$.

\begin{tabular}{|c|c|}
\hline Patient demographics & Participant, n (\%) \\
\hline \multicolumn{2}{|l|}{ Gender } \\
\hline Female & $10(38)$ \\
\hline Male & $16(62)$ \\
\hline \multicolumn{2}{|l|}{ Ethnicity } \\
\hline Anglo Australian & $14(54)$ \\
\hline Chinese & $4(15)$ \\
\hline Indian & $2(8)$ \\
\hline Italian & $2(8)$ \\
\hline Trinidad and Tobago & $1(4)$ \\
\hline UK migrant & $1(4)$ \\
\hline Indonesian & $1(4)$ \\
\hline Sri Lankan & $1(4)$ \\
\hline \multicolumn{2}{|l|}{ Age (years) } \\
\hline$<60$ & $2(8)$ \\
\hline $60-64$ & $3(12)$ \\
\hline $65-69$ & $3(12)$ \\
\hline $70-74$ & $6(23)$ \\
\hline $75-79$ & $7(27)$ \\
\hline $80-84$ & $2(8)$ \\
\hline $85-89$ & $3(12)$ \\
\hline \multicolumn{2}{|l|}{ Using insulin } \\
\hline Yes & $16(62)$ \\
\hline No & $10(38)$ \\
\hline \multicolumn{2}{|c|}{ Major comorbidity (self-identified) } \\
\hline Cardiovascular conditions & $12(46)$ \\
\hline Dyslipidemia & $3(12)$ \\
\hline Kidney conditions & $3(12)$ \\
\hline Ocular conditions & $2(8)$ \\
\hline Thyroid conditions & $2(8)$ \\
\hline Prostate conditions & $1(4)$ \\
\hline Mental health conditions & $1(4)$ \\
\hline Osteoporosis & $1(4)$ \\
\hline Traumatic injury & $1(4)$ \\
\hline \multicolumn{2}{|l|}{ Duration of illness (years) } \\
\hline$<10$ & $3(12)$ \\
\hline $10-14$ & $5(19)$ \\
\hline $15-19$ & $5(19)$ \\
\hline $20-24$ & $5(19)$ \\
\hline $25-29$ & $3(12)$ \\
\hline$>29$ & $5(19)$ \\
\hline \multicolumn{2}{|l|}{ Number of comorbidities } \\
\hline 1 & $4(15)$ \\
\hline
\end{tabular}




\begin{tabular}{ll}
\hline Patient demographics & Participant, $\mathrm{n}(\%)$ \\
\hline 2 & $9(35)$ \\
3 & $1(4)$ \\
4 & $4(15)$ \\
5 & $3(12)$ \\
$6-10$ & $4(15)$ \\
$>10$ & $1(4)$ \\
Employment & $18(69)$ \\
Retired & $3(12)$ \\
Self-employed & $5(19)$ \\
Employed by others & \\
\hline
\end{tabular}

\section{Phases in the Chronic Illness Trajectory}

Table 2 outlines the nine phases in the Chronic Illness Trajectory Model, their definitions [16], and example quotes from our cohort. Table 3 lists the patient work tasks involved in each phase. From our participants, we identified examples of patient work tasks in the following phases: trajectory onset, stable, unstable, acute, crisis, and comeback. More quotes supporting each of the phases can be found in Multimedia Appendix 2 . Details of patient work tasks can be found in our previous review [16], which outlines the different task categories, how the categories were defined and created, and what examples were available for each category.

The pretrajectory phase represents the presymptomatic period before symptom presentation. We did not include this phase in our analysis or reporting.

Table 2. Phases within the chronic illness trajectory with definitions and examples.

\begin{tabular}{|c|c|c|c|}
\hline Phase & Definition & Themes & Examples quotes \\
\hline Pretrajectory & Before symptom presentation & $\mathrm{N} / \mathrm{A}^{\mathrm{a}}$ & N/A \\
\hline Trajectory onset & $\begin{array}{l}\text { Initial symptom presentation and } \\
\text { diagnosis }\end{array}$ & $\begin{array}{l}\text { Participants respond to the new } \\
\text { diagnosis by contacting health } \\
\text { professionals and receiving new } \\
\text { information. }\end{array}$ & $\begin{array}{l}\text { "[The endocrinologists] give us a list of what to eat and } \\
\text { what not to eat. But sometimes you do it, sometimes you } \\
\text { don't." [P13, female, age } 78 \text { years] }\end{array}$ \\
\hline Stable & $\begin{array}{l}\text { Symptoms are under control and } \\
\text { life activities continue within the } \\
\text { limitations of the symptoms }\end{array}$ & $\begin{array}{l}\text { Participants try to overcome iner- } \\
\text { tia and find a new normal to dis- } \\
\text { cover what works for them. }\end{array}$ & $\begin{array}{l}\text { "There's a group online, about } 200 \text { people that have all } \\
\text { done low-carb [diet], lost } 100 \text { pounds...and got their blood } \\
\text { A1Cs right down. It seems to be the answer to me." [P14, } \\
\text { male, age } 63 \text { years] }\end{array}$ \\
\hline Unstable & $\begin{array}{l}\text { Symptoms start to get out of } \\
\text { control and life activities are ad- } \\
\text { justed to cope with increasing } \\
\text { health demands }\end{array}$ & $\begin{array}{l}\text { Participants react to instability, } \\
\text { taking up new tasks, new tools, } \\
\text { and new information. }\end{array}$ & $\begin{array}{l}\text { "I'm probably on about } 14 \text { [medications] at the moment, } \\
\text { because I've just had to add two tablets too...when I had } \\
\text { my bloods done for my endocrinologist, it came back and } \\
\text { I'm very low on iron...he's put me on iron tablets." [P6, } \\
\text { female, age } 72 \text { years] }\end{array}$ \\
\hline Acute & $\begin{array}{l}\text { Severe exacerbations of symp- } \\
\text { toms that require normal life ac- } \\
\text { tivities to be paused }\end{array}$ & $\begin{array}{l}\text { Participants rely on others to } \\
\text { maintain basic functionality by } \\
\text { prioritizing certain health needs } \\
\text { over others. }\end{array}$ & $\begin{array}{l}\text { "When I got told I'm going to be on dialysis, well I had a } \\
\text { lot of trouble trying to accept that and kept avoiding it, } \\
\text { until I was so sick I had to go on it." [P11, male, age } 76 \\
\text { years] }\end{array}$ \\
\hline Crisis & $\begin{array}{l}\text { A critical or life-threatening situ- } \\
\text { ation where urgent medical care } \\
\text { is required }\end{array}$ & $\begin{array}{l}\text { Participants cannot conduct self- } \\
\text { management and can only react } \\
\text { to crisis points. }\end{array}$ & $\begin{array}{l}\text { "I was not allowed to eat anything. I was not allowed to } \\
\text { even drink water, because there was a possibility for surgery } \\
\text { at that time." [P1, male age } 67 \text { years] }\end{array}$ \\
\hline Comeback & $\begin{array}{l}\text { Gradually return to an acceptable } \\
\text { level of everyday life }\end{array}$ & $\begin{array}{l}\text { Participants adopt to long-lasting } \\
\text { changes and deal with mental } \\
\text { distress during adjustment to a } \\
\text { new normal. }\end{array}$ & $\begin{array}{l}\text { "Just getting you out of bed and walking, just walking up } \\
\text { the end of the corridor and back and that used to exhaust } \\
\text { me. But once it's all over and done with you feel fine. Two } \\
\text { weeks of rehab." [P17, male, age } 70 \text { years] }\end{array}$ \\
\hline Downward & Consistent decline in health & N/A & N/A \\
\hline Dying & Final days before death & N/A & N/A \\
\hline
\end{tabular}

${ }^{\mathrm{a}} \mathrm{N} / \mathrm{A}$ : not applicable. 
Table 3. Patient work tasks involved in each phase.

\begin{tabular}{|c|c|c|c|c|c|c|}
\hline \multirow[t]{2}{*}{ Tasks } & \multicolumn{6}{|l|}{ Phase } \\
\hline & Trajectory onset & Stable & Unstable & Acute & Crisis & Comeback \\
\hline Planning & & $\boldsymbol{J}^{\mathrm{a}}$ & $\checkmark$ & & & \\
\hline Proactive management of risks & & $\checkmark$ & $\checkmark$ & & & $\checkmark$ \\
\hline Deliberate distraction & & $\checkmark$ & & & & \\
\hline Adapt to social values and expectations & & $\checkmark$ & & & & $\checkmark$ \\
\hline Creating mental coping strategies & $\checkmark$ & $\checkmark$ & $\checkmark$ & & & $\checkmark$ \\
\hline Learning about the disease & $\checkmark$ & $\checkmark$ & $\checkmark$ & $\checkmark$ & & \\
\hline Diet control & $\checkmark$ & $\checkmark$ & $\checkmark$ & & & \\
\hline Taking treatment & $\checkmark$ & $\checkmark$ & $\checkmark$ & $\checkmark$ & $\checkmark$ & $\checkmark$ \\
\hline Conduct exercise & & $\checkmark$ & & & & $\checkmark$ \\
\hline Monitor signs and symptoms & $\checkmark$ & $\checkmark$ & $\checkmark$ & & & $\checkmark$ \\
\hline Medication management & & $\checkmark$ & $\checkmark$ & & & $\checkmark$ \\
\hline Self-manage comorbidities & & $\checkmark$ & $\checkmark$ & & & \\
\hline Use and maintain assistive devices & & $\checkmark$ & $\checkmark$ & & & $\checkmark$ \\
\hline Do-it-yourself symptom management tools & & $\checkmark$ & $\checkmark$ & & & \\
\hline Alter the physical environment & & $\checkmark$ & & & & $\checkmark$ \\
\hline Seek medical help & $\checkmark$ & $\checkmark$ & $\checkmark$ & $\checkmark$ & $\checkmark$ & $\checkmark$ \\
\hline Ask for help from family and friends & & $\checkmark$ & $\checkmark$ & $\checkmark$ & $\checkmark$ & $\checkmark$ \\
\hline Hire professional help & & $\checkmark$ & $\checkmark$ & & & $\checkmark$ \\
\hline Consult complementary therapy & & $\checkmark$ & $\checkmark$ & & & $\checkmark$ \\
\hline Search for and attend patient support groups & $\checkmark$ & $\checkmark$ & $\checkmark$ & & & \\
\hline Teach others about their health & & $\checkmark$ & & & & \\
\hline
\end{tabular}

${ }^{\mathrm{a}}$ The patient work task is involved.

The trajectory onset phase represented when participants first became symptomatic and entered the health system. This phase primarily focused on patients with a gradual disease onset in the Chronic Illness Trajectory Model and was associated with tasks such as visiting doctors and trying to understand medical information. In the stable phase, participants spent the longest time and conducted the most patient work, with a large variety of tasks identified according to our previous publication [16] such as diet control, monitoring signs and symptoms, attending patient support groups, and planning for a new routine.

As health conditions worsen, participants may enter and exit the unstable phase repeatedly, with the goal of patient work being returning to the stable phase. Participants responded to changing health demands in the unstable phase, visiting medical professionals more frequently and starting to use support devices such as walking canes.

The acute and crisis phases represented severe and life-threatening illnesses, respectively. The participants were typically hospitalized during this period. They conducted no patient work, and health professionals oversaw their well-being. In the comeback phase, where recovery and rehabilitation occurred, patient work focused on transitioning back to the stable phase, with specific tasks such as rehabilitating exercises

or coping with mental trauma. Under most circumstances, participants would not return to their previous levels of health after an acute, a crisis, or a comeback cycle. Some participants may experience this cycle repeatedly in their lives.

The final two stages of the model, the downward phase (an irreversible deterioration in health) and the dying phase (the last few days before death) were not observed in this study.

\section{Different Types of Chronic Illness Trajectories}

\section{Overview}

Participants experienced different patterns of change in their illnesses. Some remained stable for most of their disease trajectories, whereas others experienced many crisis episodes. We identified four unique trajectories in our cohort (Figure 2). Each trajectory represented a different life experience and required a different style of patient work adaptation. Each trajectory was also associated with unique goals and needs (Table 4). Multimedia Appendix 3 includes quotes supporting each trajectory. As participants are not at the end of the illness trajectory, it is possible that each participant could experience more than one trajectory in their lifetime. However, given that we are only able to capture past data and cannot predict future events, only the trajectory that each participant was experiencing at the time of the interview was reported here. 
Figure 2. Visual representation of the four trajectories.

Type 1 trajectory

(14 participants)

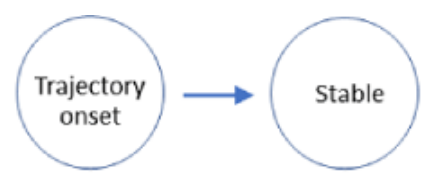

Type 2 trajectory

(7 participants)

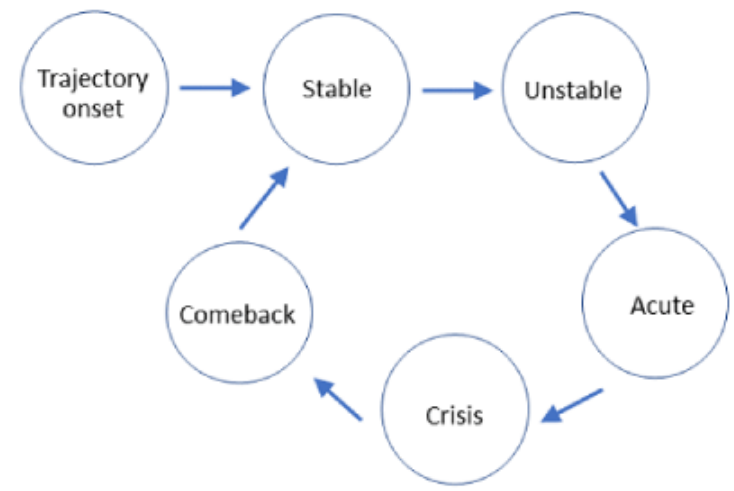

Type 3 trajectory

(3 participants)

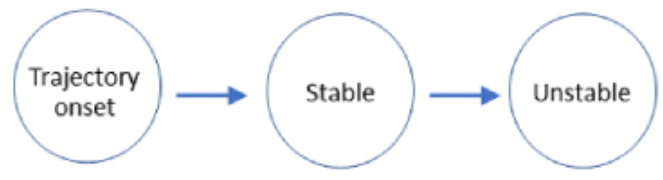

Type 4 trajectory

(2 participants)

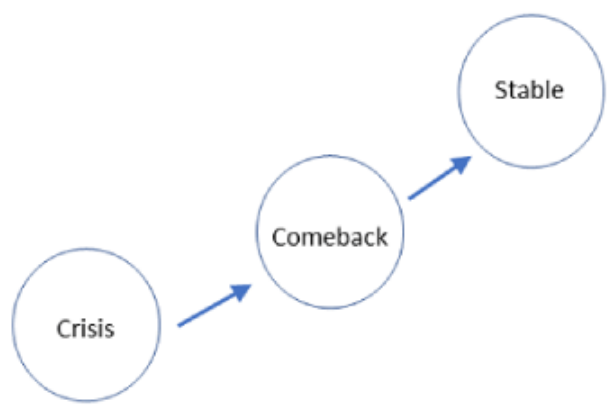

Table 4. Trajectory types and their characteristics $(\mathrm{N}=26)$.

\begin{tabular}{|c|c|c|c|c|}
\hline Trajectory type & Explanation & Work goals & $\begin{array}{l}\text { Participant } \\
\text { IDs }\end{array}$ & $\begin{array}{l}\text { Number of comor- } \\
\text { bidities, mean } \\
\text { (SD) }\end{array}$ \\
\hline $\begin{array}{l}\text { Living with sta- } \\
\text { ble chronic con- } \\
\text { ditions }\end{array}$ & $\begin{array}{l}\text { Trajectory onset } \rightarrow \text { stable (participants were diagnosed at a mild stage of } \\
\text { the disease where conditions were stable and did not experience disease } \\
\text { exacerbations). }\end{array}$ & $\begin{array}{l}\text { Making patient } \\
\text { work as routinized } \\
\text { and invisible as } \\
\text { possible. }\end{array}$ & $\begin{array}{l}7,9,10,14 \\
15,19,20,22 \\
23,25, \text { and } 26\end{array}$ & $3.2(1.7)$ \\
\hline $\begin{array}{l}\text { Dealing with } \\
\text { cycles of acute } \\
\text { or crisis } \\
\text { episodes }\end{array}$ & $\begin{array}{l}\text { Trajectory onset } \rightarrow \text { stable } \rightarrow \text { unstable } \rightarrow \text { acute } \rightarrow \text { crisis } \rightarrow \text { comeback } \rightarrow \text { stable } \\
\text { (participants have experienced episodes of disease exacerbation, sometimes } \\
\text { repeatedly). }\end{array}$ & $\begin{array}{l}\text { Heavily multimor- } \\
\text { bid, experiencing } \\
\text { polypharmacy, and } \\
\text { requiring support } \\
\text { with self-manage- } \\
\text { ment adherence. }\end{array}$ & $\begin{array}{l}2,3,4,8,11 \\
12,13,17,18 \\
\text { and } 21\end{array}$ & $3.4(1.7)$ \\
\hline $\begin{array}{l}\text { Responding to } \\
\text { unstable } \\
\text { changes in their } \\
\text { conditions }\end{array}$ & $\begin{array}{l}\text { Trajectory onset } \rightarrow \text { stable } \rightarrow \text { unstable (participants were diagnosed at a mild } \\
\text { stage but are currently experiencing a decline in health). }\end{array}$ & $\begin{array}{l}\text { Experiencing in- } \\
\text { creasing intensity } \\
\text { and variety of pa- } \\
\text { tient work and } \\
\text { dealing with rapid } \\
\text { changes. }\end{array}$ & 6,16 , and 24 & $8.7(9.7)$ \\
\hline $\begin{array}{l}\text { Coming back } \\
\text { from crisis be- } \\
\text { fore stabilizing }\end{array}$ & $\begin{array}{l}\text { Crisis } \rightarrow \text { comeback } \rightarrow \text { stable (participants were diagnosed due to a sudden } \\
\text { and severe exacerbation and recovered from that crisis). }\end{array}$ & $\begin{array}{l}\text { Cope with a total } \\
\text { loss of normal life } \\
\text { and needing holis- } \\
\text { tic support. }\end{array}$ & 1 and 5 & $1.5(0.7)$ \\
\hline
\end{tabular}




\section{Type 1: Living With Stable Chronic Conditions}

The trajectory type most common in our cohort was for those participants who experienced many years of stability with their disease (14/26, 54\% of participants). These participants had only experienced the trajectory onset and stable phases (Figure 2) without disease exacerbation. Their work goal was to maximize the integration of patient work into daily life, making patient work as routinized and invisible as possible.

Participants in this trajectory type were diagnosed at a mild stage of the disease. They had sufficient opportunity to experiment with patient work tasks, having tried different food options, exercise routines, medications, or information sources, for example. As this group had spent many years in the stable phase, these participants regarded patient work as an incorporated part of their lives. Some participants reported that their patient work had become so ingrained, they no longer remembered each medication's purpose or the roles of the health practitioner they were seeing. Participants averaged 3.2 (SD 3.8) comorbidities in this trajectory, indicating a relatively mild stage of health deterioration.

\section{Type 2: Dealing With Cycles of Acute or Crisis Episodes}

The second most common trajectory type was observed in participants who experienced at least one incidence of acute or critical exacerbation followed by the comeback phase $(7 / 26$, $27 \%$ of participants). Apart from the phases experienced by participants in the type 1 trajectory, the type 2 trajectory also included experiences in the unstable, acute, crisis, and comeback phases (Figure 2). The work goal for this group revolved around being heavily multimorbid, experiencing polypharmacy, and requiring support with self-management adherence.

This type of trajectory described participants who had major critical episodes, such as strokes or heart attacks, at least once. Some participants experienced multiple critical episodes and accumulated more medications and diagnoses. Interestingly, due to their complicated medical histories, many participants in this trajectory type had an excellent understanding of medical information. They were aware of the biochemical principles behind their disease and medications but required managerial support to follow their complicated patient work routines. Participants averaged 3.4 (SD 1.7) comorbidities in this trajectory, suggesting a similar level of well-being to the type 1 trajectory group.

\section{Type 3: Responding to Unstable Changes in Their Conditions}

The third trajectory type included participants currently in the unstable phase $(3 / 26,12 \%$ of participants). These participants would eventually either proceed onto the acute, crisis, or comeback cycle, or recover enough to return to the stable phase. However, at the time when the interviews were conducted, this group experienced fluctuating health states and had specific work goals and user needs (Figure 2). Their patient work goals showed increasing intensity and variety of patient work and dealing with rapid changes.

Owing to their rapidly changing health, participants in this trajectory were seeing their doctors nonroutinely and frequently, with many changes being made to their treatment regimen in a short timeframe. These participants reported confusion regarding the purpose of their treatment and struggled to keep up with their health, often having to rapidly adopt assistive devices (eg, walking canes) or external helpers (eg, hired cleaners). These patients felt that their health was taking over all other spheres of life and required help with understanding how their health was progressing. Participants averaged 8.7 comorbidities (SD 9.7) in this trajectory, significantly higher than the number of comorbidities experienced by the previous two types and suggesting a worse stage of health.

As these participants are currently experiencing exacerbation in health, it is impossible to determine which phase and trajectory they will end up in. For most participants experiencing this trajectory, it is the first time they experience exacerbation, thus lacking the experience and familiarity that participants from the type 2 trajectory may have derived from previous experiences with worsening health. Therefore, we made a distinction for this group of participants, acknowledging the difficulties and stress associated with responding to unstable changes in their health.

\section{Type 4: Coming Back From Crisis Before Stabilizing}

The least common trajectory type in our cohort was the participants who received their diagnosis during a crisis event (2/26, $8 \%$ of participants). Unlike the other three trajectories, this group initiated their trajectory during the crisis phase (Figure 2 ), such as with a heart attack or a traffic accident. Their patient work goals focused on coping with a total loss of normal life and needing holistic support.

During the crisis phase, the participants were hospitalized for prolonged periods with little to no autonomy. As participants slowly recovered in the comeback phase, they reported experiencing great psychological trauma as they came to understand the irreparable changes in their health. Some participants indicated that they were incapable of coping with these changes during the comeback phase and experienced a range of negative emotions such as dread, devastation, powerlessness, or denial. Suicidal ideation, depression, and thoughts about death were explicitly mentioned. Participants averaged 1.5 comorbidities (SD 0.7) in this trajectory, the lowest number of all types, due to their recent diagnosis and being situated at a relatively earlier stage of the journey of illness despite having experienced significant trauma.

This category of participants did not strictly adhere to the chronic illness trajectory, as participants were not diagnosed at a mild stage of the disease. They also differed from the type 2 trajectory as they did not experience living with their condition in a controlled manner before symptoms worsened and began to go out of control. They do not have the knowledge taught to them by clinicians at diagnosis during the trajectory onset phase and had to learn about self-management while coping with trauma and recovery. Therefore, they have been given a distinct category to reflect their lack of familiarity with this newly diagnosed condition and the few resources compared with those of the other three trajectories previously discussed. 


\section{Discussion}

\section{Principal Findings}

Determining the support needs of multimorbid patients self-managing in the community is an important initial step in designing digital interventions for them. Chronic comorbidities are extremely common in the type 2 diabetes population, with studies indicating that up to $97.5 \%$ of patients have one comorbid condition and $88.5 \%$ have at least two [20,21]. Our participants were also predominantly affected by comorbidities considered to be concordant with the pathophysiology of type 2 diabetes [22], such as cardiovascular diseases, dyslipidemia, kidney conditions, and ocular conditions. This group represents a population in the community burdened with significant patient work and poses major financial challenges to the health care system if not well-managed. Currently, health apps for chronic patients in the community either target broad populations, such as patients with heart failure, or narrowly defined subgroups, such as patients recently discharged following total knee replacement [23]. Our findings indicate chronic multimorbid patients, such as those with type 2 diabetes, have support needs that evolve over time and are much more complex than those currently supported. As such, a generic app for a certain disease cannot realistically support the differing needs of all patients irrespective of the phase or trajectory type they are in.

Our data revealed four distinct trajectory types over time that produced different self-management goals and work goals, further dissecting chronic multimorbid patients into subgroups based on their previous medical experience. Designing for patient needs from a viewpoint that includes previous medical history and current state is therefore likely to improve user acceptability and appropriateness of digital health apps, enabling such digital tools to provide more timely, suitable, and actionable advice.

\section{Designing for Phase-Specific Needs}

Our study indicates that the range and intensity of patient work varies at different phases of the Chronic Illness Trajectory Model. Digital interventions that seek to optimize self-management should therefore be designed according to the specific needs of each phase and acknowledge that different types of support are required for different tasks in each phase.

Studies have begun to address this, moving away from generic all-patient user groups, with recent studies designing specific digital tools for newly diagnosed people with diabetes [24] and for people recovering from trauma [25], for example. Such studies have already uncovered significant differences in the subpopulations [11]. Patients using apps also report that as their self-management behaviors change, they can outgrow the apps that helped them early in their illness trajectory [26], resulting in continuously seeking out new apps. In our data, patients described different tasks and needs at various phases of the chronic illness trajectory. In the trajectory onset phase, patients commonly thought that the medical information provided was too generic, too technical, and did not translate into actionable suggestions in their own lives. This can be supported by giving personally relevant, precise, and clear advice (such as eat less bread and walk up and down the stairs during lunch break instead of eat less carbohydrates or do more exercise). During the unstable phase, patients were compelled to take risk management measures in aspects of life previously taken for granted, such as taping carpets to the floor to prevent slipping or putting rubber bands around stair banisters to feel the stairs at night. Patients in this phase need more information about what is happening to them and what they need to look out for on a daily basis, provided in lay language. The acute and crisis phases produced significant restrictions and burden to patients and their families, with participants describing having to conduct all activities on the mandate of doctors and feeling shattered or having a lot of trouble trying to accept it. Patients in these phases need mental health support and clear and actionable advice to reduce any chance of confusion or mismanagement. The comeback phase was described as a new lifestyle, with major adjustments to life needed to accommodate changes in routines, such as rehabilitation schedules or dialysis. Patients need logistical support at this stage, such as finding out how to obtain a wheelchair or arrange for subsidized transport, to cope with their reduced health state.

\section{Designing for Trajectories}

The four types of trajectories identified in this study correspond to four distinctive design patterns. Each design needs to be tailored to the intended user's needs, digital literacy, environment, and whether the user is the patient or their caregiver. On the basis of the work goals identified in Table 4 and Multimedia Appendix 3, we present the digital needs of the four trajectories in Table 5, together with potential tools that can address their needs. Patients may also shift from one trajectory type to another as their health changes over time, with their need for digital technology changing accordingly. 
Table 5. Digital user needs and recommendations for each trajectory type.

\begin{tabular}{lll}
\hline Trajectory types & User needs & Potential digital tools \\
\hline $\begin{array}{l}\text { Type 1: living with stable } \\
\text { chronic conditions }\end{array}$ & $\begin{array}{l}\text { Tools that normalize patient work and remove } \\
\text { the burden of having to think about the disease }\end{array}$ & $\begin{array}{l}\text { Background data collection tools that require no user input (eg, step- } \\
\text { counting phone apps) [27] }\end{array}$ \\
& $\begin{array}{l}\text { Integrated, predetermined lifestyle changes and health intervention } \\
\text { delivered automatically (eg, smart fridges that order specific groceries } \\
\text { based on existing algorithms and automated prescription refill and } \\
\text { delivery) [28] }\end{array}$
\end{tabular}

Type 2: dealing with cy- Tools that support self-management adherence cles of acute or crisis and monitors health episodes

Type 3: responding to unstable changes in their conditions
Tools that provide symptom monitoring and give alarms for health deterioration

$\bullet$

Medication adherence support tools (eg, context-aware digital reminders that cue for medication taking immediately before meals)

- Crisis prevention technologies (eg, health monitoring tools that use predictive algorithms to observe signs, such as food and medication consumption, and generate alarms based on behavioral changes)

- Crisis prevention technologies (eg, health monitoring tools that use predictive algorithms to observe signs, such as changes in physical symptoms and emotional states, and generate alarms based on symptom changes)

- Scheduling and communication assistance (eg, apps that can manage a complicated and changing timetable involving multiple clinicians)

Type 4: coming back from crisis before stabilizing
Tools that support coping with a total loss of normal life and guide patients toward appropriate services and support infrastructure to reestablish normalcy
- Guide the patient to seek appropriate social services (eg, direct patients to appropriate social, financial, and legal services)

- $\quad$ Provide support with mental health and coping (eg, phone-based mental health support apps)

\section{Designing for Phase Change}

Digital tools that aim to be used throughout the duration of a disease's chronic illness trajectory will need to detect phase changes, such as when the patient's health worsens from the stable to the unstable phase. Although collaborative, co-design exercises with patients to gain insight into user needs are now common during digital health app development, the circumstances of the patients' health do not remain immutable after the app's release. Tools to capture patient-reported experience measure and patient-reported outcome measure $[29,30]$ can collect self-reported data at preset points of the day or immediately after predefined trigger events and can assist with keeping up to date with the patient's health after the app's release. Ideally, an app that detects phase changes should alter its functionality accordingly by activating submodules. For example, participants interviewed for an app designed for mental health expressed a desire for the app to send them mood-regulating messages at times when they were about to lose their temper [31]. This can be achieved either through purely automatic detection of worsening biophysical signs (such as constantly elevated blood pressure or lopsided gait) via external sensors, regular self-reporting by the patient, wearable smart household items such as smart mattresses or smart watches or using individual user data as baselines to train algorithms. Although such data can be entered into digital devices by the patient, automated data collection would reduce the health-related burden of self-monitoring. Excessive requirements for self-reported data could make digital interventions burdensome and contribute to disengagement and dropout over time. Other innovative, context-sensitive digital health interventions, such as Smart Pill Bottles that can detect irregularities in medication consumption $[32,33]$, also have the potential to be integrated into a home system that generates external data complementing phone-based apps.

When the interviews took place, each participant's trajectory described the person's current state and journey to this point from the onset of their health conditions, with the future states of each person not necessarily known. Should future research discover these phases and trajectory types to be predictable based on medical history, digital tools can be designed to anticipate such changes and variations between different patients. Individualized and customizable apps [34,35] allow for further tailoring to fit specific subpopulations, and designs of self-care tools would need to adapt to the patient's evolving digital needs to ensure relevance and integration into patient work.

For full realization and evaluation of any of the design implications suggested in this section, co-design sessions would have to be conducted with participants living in the targeted chronic condition, which is beyond the scope of this paper. However, the design implications highlighted here can serve to trigger discussion toward more innovative, holistic, and responsive digital intervention design during co-design sessions, particularly as very few digital interventions currently adapt to changing needs and trajectories.

\section{Limitations}

This study was limited in terms of data collection. First, we only recruited participants with a clinical diagnosis who were not severely ill and asked them to recall patient work from the time of diagnosis rather than recruiting individuals at different phases of the chronic illness trajectory. This was done to understand how patient work has evolved for each person. Second, our sample included more males than females because more females declined participation due to family concerns or 
obligations. Finally, our recruitment criteria stated that participants must be fluent in English. Consequently, the patient work of people who were not fluent in English was not captured.

\section{Conclusions}

This study provides insights into how patient work among multimorbid patients with type 2 diabetes changes over time. There are still gaps in our understanding of how patient health care goals change through different phases of their health, how different patients have different disease trajectories, and how digital health apps can adjust to such changes over time. This study presents data on different types of trajectories, with the perspective of how to use such findings to design better consumer-facing digital health apps. Our findings revealed four different types of trajectories, resulting in different patient work goals. Patients who had never experienced disease exacerbation desired for patient work to be as invisible as possible, whereas those who lived through cycles of crises and recovery needed assistance with self-management adherence. Participants currently experiencing a decline in health needed timely support and crisis prevention technology, and those diagnosed during severe crisis needed guidance to find sources of support and coping. This study highlights opportunities for health informatics and design communities to explore the untapped space of designing for time and trajectory, where future research should incorporate an individual's evolving health experiences when designing digital technologies for patient work over time.

\section{Acknowledgments}

The authors would like to thank Mr Wen Jun Liang, Mr Joshua Haddrill, Ms Isabelle Barnes, Mr Christian Tran, Mr Jiawei He, Ms Navy Sea, Ms Emile Chien-Ai Chou, and Ms Natasha Hughes for working as research assistants and acting as chaperones during the interviews. The authors would also like to thank Professor Bernard Tuch, Dr Priscilla Wong, Dr Veronica Prada, and Mr Ivan Khizhnyak for their invaluable help with recruitment. The screenshot conversion software was written by Mr Wen Jun Liang and Mr Joshua Haddrill, without which this study would not have been technically possible. The authors would like to thank Ms Melissa Park for editing earlier versions of the manuscript. Most importantly, the authors would like to thank their participants for their indispensable assistance. They thank the participants for their generosity and kindness, for sharing their stories with us, and for allowing them to record a glimpse of their lives. AYSL was supported by the New South Wales Health Early-to-Mid Career Fellowship, and her research was supported by the National Health and Medical Research Council (NHMRC) Centre for Research Excellence in Digital Health (APP1134919) and NHMRC Centre of Research Excellence in Digital Technology to Transform Chronic Disease Outcomes (ID 1170937). This research was supported by the NHMRC Centre for Research Excellence in Digital Health (APP1134919).

\section{Authors' Contributions}

Study conceptualization was carried out by AYSL and KY. Study design was developed by AYSL and KY. Recruitment was carried out by KY, JJ, KWKH, SV, and AYSL. Interviews were conducted by KY, JJ, and AYSL. Data analysis was performed by KY, JJ, AYSL, and EC. The first draft was created by KY, JJ, and AYSL and subsequent drafts by KY, EC, AYSL, KWKH, $\mathrm{SV}, \mathrm{AB}$, and FR.

\section{Conflicts of Interest}

None declared.

\section{Multimedia Appendix 1}

Interview question guide.

[DOC File, 32 KB-Multimedia Appendix 1]

\section{Multimedia Appendix 2}

Quote table for different phases.

[DOC File, 46 KB-Multimedia Appendix 2]

\section{Multimedia Appendix 3}

Quote table for different trajectories.

[DOC File , 51 KB-Multimedia Appendix 3]

\section{References}

1. Holden RJ, Valdez RS, Schubert CC, Thompson MJ, Hundt AS. Macroergonomic factors in the patient work system: examining the context of patients with chronic illness. Ergonomics 2016 May 10:1-18. [doi: 10.1080/00140139.2016.1168529] [Medline: 27164171] 
2. Valdez RS, Holden RJ, Novak LL, Veinot TC. Transforming consumer health informatics through a patient work framework: connecting patients to context. J Am Med Inform Assoc 2015 Jan;22(1):2-10. [doi: 10.1136/amiajnl-2014-002826] [Medline: 25125685]

3. Corbin J, Strauss A. Managing chronic illness at home: three lines of work. Qual Sociol 1985;8(3):224-247. [doi: 10.1007/bf00989485]

4. Corbin J, Strauss A. Unending Work and Care: Managing Chronic Illness at Home. 1st Edition. San Francisco: Jossey-Bass; 1988:1-384.

5. Corbin J. The corbin and strauss chronic illness trajectory model: an update. Sch Inq Nurs Pract 1998;12(1):33-41. [Medline: 9805470]

6. Halcomb E, Davidson P. Using the illness trajectory framework to describe recovery from traumatic injury. Contemp Nurse 2005;19(1-2):232-241. [doi: 10.5172/conu.19.1-2.232] [Medline: 16167451]

7. Reed E, Corner J. Defining the illness trajectory of metastatic breast cancer. BMJ Support Palliat Care 2015 Dec;5(4):358-365 [FREE Full text] [doi: 10.1136/bmjspcare-2012-000415] [Medline: 24644176]

8. Burton CR. Re-thinking stroke rehabilitation: the Corbin and Strauss chronic illness trajectory framework. J Adv Nurs 2000 Sep;32(3):595-602. [doi: 10.1046/j.1365-2648.2000.01517.x] [Medline: 11012801]

9. Miller CM. Trajectory and empowerment theory applied to care of patients with multiple sclerosis. J Neurosci Nurs 1993 Dec;25(6):343-348. [doi: 10.1097/01376517-199312000-00004] [Medline: $\underline{\text { 8106827] }}$

10. Beeney LJ, Bakry AA, Dunn SM. Patient psychological and information needs when the diagnosis is diabetes. Patient Educ Couns 1996 Oct;29(1):109-116. [doi: 10.1016/0738-3991(96)00939-1] [Medline: 9006227]

11. Grobosch S, Kuske S, Linnenkamp U, Ernstmann N, Stephan A, Genz J, GDS Group. What information needs do people with recently diagnosed diabetes mellitus have and what are the associated factors? A cross-sectional study in Germany. BMJ Open 2018 Oct 31;8(10):e017895 [FREE Full text] [doi: 10.1136/bmjopen-2017-017895] [Medline: 30385437]

12. Murphy RP. Management of diabetic retinopathy. Am Fam Physician 1995 Mar;51(4):785-796. [Medline: 7887355]

13. Henricsson M, Nilsson A, Janzon L, Groop L. The effect of glycaemic control and the introduction of insulin therapy on retinopathy in non-insulin-dependent diabetes mellitus. Diabet Med 1997 Feb;14(2):123-131. [doi: 10.1002/(SICI)1096-9136(199702)14:2<123::AID-DIA306>3.0.CO;2-U] [Medline: 9047089]

14. Baptista S, Wadley G, Bird D, Oldenburg B, Speight J, My Diabetes Coach Research Group. User experiences with a type 2 diabetes coaching app: qualitative study. JMIR Diabetes 2020 Jul 17;5(3):e16692 [FREE Full text] [doi: 10.2196/16692] [Medline: 32706649]

15. Yin K, Harms T, Ho K, Rapport F, Vagholkar S, Laranjo L, et al. Patient work from a context and time use perspective: a mixed-methods study protocol. BMJ Open 2018 Dec 22;8(12):e022163 [FREE Full text] [doi: 10.1136/bmjopen-2018-022163] [Medline: $\underline{30580259]}$

16. Yin K, Jung J, Coiera E, Laranjo L, Blandford A, Khoja A, et al. Patient work and their contexts: scoping review. J Med Internet Res 2020 Jun 02;22(6):e16656 [FREE Full text] [doi: 10.2196/16656] [Medline: 32484449]

17. Kocaballi AB, Ijaz K, Laranjo L, Quiroz JC, Rezazadegan D, Tong HL, et al. Envisioning an artificial intelligence documentation assistant for future primary care consultations: a co-design study with general practitioners. J Am Med Inform Assoc 2020 Nov 01;27(11):1695-1704 [FREE Full text] [doi: 10.1093/jamia/ocaa131] [Medline: 32845984]

18. Hernandez NV, Shah JJ, Smith SM. Understanding design ideation mechanisms through multilevel aligned empirical studies. Des Stud 2010 Jul;31(4):382-410. [doi: 10.1016/j.destud.2010.04.001]

19. Tomitsch M, Wrigley C, Borthwick M, Ahmadpour N, Frawley J, Kocaballi A, et al. Design. Think. Make. Break. Repeat.: A Handbook of Methods. London, United Kingdom: Laurence King Publishing; 2021:1-160.

20. Iglay K, Hannachi H, Howie PJ, Xu J, Li X, Engel SS, et al. Prevalence and co-prevalence of comorbidities among patients with type 2 diabetes mellitus. Curr Med Res Opin 2016 Jul;32(7):1243-1252. [doi: 10.1185/03007995.2016.1168291] [Medline: 26986190]

21. Lang VB, Marković BB. Prevalence of comorbidity in primary care patients with type 2 diabetes and its association with elevated HbA1c: a cross-sectional study in Croatia. Scand J Prim Health Care 2016;34(1):66-72 [FREE Full text] [doi: 10.3109/02813432.2015.1132886] [Medline: 26853192]

22. Piette JD, Kerr EA. The impact of comorbid chronic conditions on diabetes care. Diabetes Care 2006 Mar;29(3):725-731. [doi: 10.2337/diacare.29.03.06.dc05-2078] [Medline: 16505540]

23. Timmers T, Janssen L, van der Weegen W, Das D, Marijnissen W, Hannink G, et al. The effect of an app for day-to-day postoperative care education on patients with total knee replacement: randomized controlled trial. JMIR Mhealth Uhealth 2019 Oct 21;7(10):e15323 [FREE Full text] [doi: 10.2196/15323] [Medline: 31638594]

24. Petersen M, Hempler NF. Development and testing of a mobile application to support diabetes self-management for people with newly diagnosed type 2 diabetes: a design thinking case study. BMC Med Inform Decis Mak 2017 Jun 26;17(1):91 [FREE Full text] [doi: 10.1186/s12911-017-0493-6] [Medline: 28651639]

25. Childs BR, Breslin MA, Nguyen MP, Simske NM, Whiting PS, Vasireddy A, et al. Implementation of a mobile app for trauma education: results from a multicenter study. Trauma Surg Acute Care Open 2020;5(1):e000452 [FREE Full text] [doi: 10.1136/tsaco-2020-000452] [Medline: 32548309] 
26. Anderson K, Burford O, Emmerton L. Mobile health apps to facilitate self-care: a qualitative study of user experiences. PLoS One 2016;11(5):e0156164 [FREE Full text] [doi: 10.1371/journal.pone.0156164] [Medline: 27214203]

27. Kim J, Ryu B, Cho S, Heo E, Kim Y, Lee J, et al. Impact of personal health records and wearables on health outcomes and patient response: three-arm randomized controlled trial. JMIR Mhealth Uhealth 2019 Jan 04;7(1):e12070 [FREE Full text] [doi: 10.2196/12070] [Medline: 30609978]

28. Luo S, Xia H, Gao Y, Jin JS, Athauda R. Smart fridges with multimedia capability for better nutrition and health. In: Proceedings of the International Symposium on Ubiquitous Multimedia Computing. 2008 Presented at: International Symposium on Ubiquitous Multimedia Computing : UMC 2008; October 13-15, 2008; Hobart, Australia p. 39-44. [doi: 10.1109/UMC.2008.17]

29. van Berkel N, Ferreira D, Kostakos V. The experience sampling method on mobile devices. ACM Comput Surv 2018 Jan 12;50(6):1-40. [doi: 10.1145/3123988]

30. Torous J, Kiang MV, Lorme J, Onnela J. New tools for new research in psychiatry: a scalable and customizable platform to empower data driven smartphone research. JMIR Ment Health 2016;3(2):e16 [FREE Full text] [doi: 10.2196/mental.5165] [Medline: 27150677]

31. Goodwin J, Cummins J, Behan L, O'Brien SM. Development of a mental health smartphone app: perspectives of mental health service users. J Ment Health 2016 Oct;25(5):434-440. [doi: 10.3109/09638237.2015.1124392] [Medline: 26732242]

32. Zijp T, Touw D, van Boven J. User acceptability and technical robustness evaluation of a novel smart pill bottle prototype designed to support medication adherence. Patient Prefer Adherence 2020 Mar; Volume 14:625-634. [doi: 10.2147/ppa.s240443]

33. DeMeo D, Morena M. Medication adherence using a smart pill bottle. In: Proceedings of the 11 th International Conference \& Expo on Emerging Technologies for a Smarter World (CEWIT). 2014 Presented at: 11th International Conference \& Expo on Emerging Technologies for a Smarter World (CEWIT); Oct. 29-30, 2014; Melville, NY, USA. [doi: 10.1109/cewit.2014.7021149]

34. Crosby LE, Ware RE, Goldstein A, Walton A, Joffe NE, Vogel C, et al. Development and evaluation of iManage: a self-management app co-designed by adolescents with sickle cell disease. Pediatr Blood Cancer 2017 Jan;64(1):139-145. [doi: 10.1002/pbc.26177] [Medline: 27574031]

35. Goldenberg T, McDougal SJ, Sullivan PS, Stekler JD, Stephenson R. Building a mobile HIV prevention app for men who have sex with men: an iterative and community-driven process. JMIR Public Health Surveill 2015;1(2):e18 [FREE Full text] [doi: 10.2196/publichealth.4449] [Medline: 27227136]

\title{
Abbreviations \\ NHMRC: National Health and Medical Research Council
}

\author{
Edited by R Kukafka; submitted 23.11.20; peer-reviewed by HC Chiu, H Rutjes, M Ozkaynak, A Ritchie, J Hill, K Blondon; comments \\ to author 28.01.21; revised version received 16.02.21; accepted 24.05.21; published 15.07.21 \\ Please cite as: \\ Yin K, Jung J, Coiera E, Ho KWK, Vagholkar S, Blandford A, Rapport F, Lau AYS \\ How Patient Work Changes Over Time for People With Multimorbid Type 2 Diabetes: Qualitative Study \\ J Med Internet Res 2021;23(7):e25992 \\ URL: https://www.jmir.org/2021/7/e25992 \\ doi: $10.2196 / 25992$ \\ PMID: $\underline{34264193}$
}

CKathleen Yin, Joshua Jung, Enrico Coiera, Kenneth W K Ho, Sanjyot Vagholkar, Ann Blandford, Frances Rapport, Annie Y S Lau. Originally published in the Journal of Medical Internet Research (https://www.jmir.org), 15.07.2021. This is an open-access article distributed under the terms of the Creative Commons Attribution License (https://creativecommons.org/licenses/by/4.0/), which permits unrestricted use, distribution, and reproduction in any medium, provided the original work, first published in the Journal of Medical Internet Research, is properly cited. The complete bibliographic information, a link to the original publication on https://www.jmir.org/, as well as this copyright and license information must be included. 